\author{
in Studies on Cardiac Structure and Metabolism. Vol. 4. pp. 375392 (Uni- \\ versity Park Press, Baltimore, 1972). \\ 20. John A Warren. Charleston S. \\ 21. This research was supported bs finited States Public llealth Service Traning \\ Grant H1. 05925-04. Research (irant HL 05435-14. and contrate vili
}

$71-2493$

22. Reyuests for reprints should be addressed to: P. ( C (illette, M.D.. Department of Cell Biophysics, Baylor College of Medicine, 1200 Moursund Ave., Hous(on. Tex. 77025 (USA)

23. Acepted for publication December 15. 1975
Amyliase calcium cystic fibrosis flow rate inorganic phosphate parotid saliva potassium sodium

\title{
Parotid Gland Function in Children with Cystic Fibrosis and Child Control Subjects
}

\author{
JEANETTI: BLOMFIEID. ${ }^{31}$ ANNE R. RUSH, HFIISN M. AI.IARS, AND JOHN M. BROWN

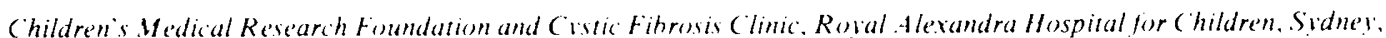 \\ Vew South Hules. Iustralia
}

\section{Extract}

Parotid saliva was collected from 22 children with cystic fibrosis (CF) and 21 control children. Stimulation was by $0.1 \mathrm{ml} 5$; citric acid on the tongue every $15 \mathrm{sec}$ over a period of $110 \mathrm{~min}$, and samples were collected for 2 -min intervals. Stimulated saliva showed a lag period of low amylase release, and an activated period of higher amylase release. The major difference between $(F$ and child control parotid saliva was in the elevated calcium concentrations in $C F$ subjects. Flow rate and amylase, although higher in the CF group. were not raised to a statistically significant level. There were higher mean values for sodium and inorganic phosphate in $\mathrm{Ct}$ children but statistical significance was minimal. Potassium values were almost identical in $\mathrm{C} F$ and control saliva. In the activated parotid saliva samples of both control and $(F$ subjects there were positive correlations between flow rate and calcium, flow rate and sodium, amvlase and calcium, and sodium and calcium, and negatice correlations between sodium and potassium. The parotid function test has no value as a diagnostic test for cystic fibrosis, as even calcium values show too much overlap with control saliva to be of diagnostic worth.

\section{Speculation}

Higher calcium values in parotid saliva of ( 1 children are likely to cause increased formation of insoluble calcium-phosphate-protein complexes within the acinar lumina and small ducts of the parotid gland and increased deposition of dental calculus on tooth surfaces adjacent to the openings of the parotid ducts.

In a previous study (5). parotid saliva collected during a short term (4-min) stimulation had show nelevalted protein. amylase. and calcium concentrations in cystic fibrosis (CF) parotid salisa compared with control saliva. The higher protein concentrations were associated with colloidal separation of sparingly soluble protein on cooling the saliva to room temperature. Subsequently, parotid saliva with high calcium concentrations has been shown to form turbid calcium-phosphate-protein complexes on standing at body temperature $(1,2)$. It has been suggested that this sparingly soluble material might be causing obstruction in parotid glands of $\mathrm{CF}$ patients (22) and excessive dental calculus on their teeth (26)

Previous comparisons of $\mathrm{CF}$ and control parotid saliva have produced conflicting results. showing thatl. in CF parotid saliva. flow rate is increased $(18)$ or not different $(4,6,13)$, protein is increased $(3,4)$ or not $(16,25)$, amylase is elevated (3., 4) or not (15). calcium is raised $(3,4,6.18 .25)$ or not $(16.18)$. sodium is higher $(4,6,12,18)$ or not $(16)$, inorganic phosphate is increased (4. 6. 16), and potassium is not different from controls (4, 6. 12. 16 . 18)

However. studies by Dawes $(8.9)$ of parotid salival of normal subjects have shown that stimulated saliva takes approximately 3 min to change from a resting to an activated state. that variation of degree of sucking lozenges influences flow rate. that flow rate influences concentrations of protein and electrolytes, and that the duration of stimulation also influences concentrations of protein and calcium. Therefore. many of the previous studies of ( $\mathrm{f}$ saliva are difficult 10 interpret. Thus variation among both $\mathrm{CF}$ and control children in rattes of chewing chicle (6). or stlcking lozenges $(16,18)$ or citric acid ersstals (12) would affect results randomly In other studies. collection times were wiable among subjects $(6)$. were not stated $(15,25)$, or were short $(3,4)$

In the present study, the stimulus was constant and operator controlled. and the effects of duration of stimulation were assessed by 2 min sampling over a 10 min period. Correlations hetween flow rate. amvlase, and inorganic components were determined in the activated saliva collected hetween $t$ and 10 min alter commenc. ing stimulation.

\section{SI:BJE(TS ANI) MLTHODS}

Parotid saliva was collected from 22 children with costic fibrosis (1 3 male and 9 female, with a mean age of 9.2 years and range of 613 years) who were altending the (ystic Fibrosis (linic at the Royal Alexandra Hospital for Children as outpatients. There were 21 control children ( 13 male and 8 female, with a mean age of 9.2 vears and range of 513 vears). who were children of members of staff and their friends. Informed consent was obtained for all subjects. 
The saliva was collected between the hours of $9 \mathrm{AM}$ and $11 \mathrm{AM}$, with a minimum of $\mathrm{l} \mathrm{hr}$ after food or drink. Parotid saliva was collected by Lashley cups (27) attached by suction over Stenson's duct. Stimulation was by $0.1 \mathrm{~m} 15 \%$ citric acid on the tongue every $15 \mathrm{sec}$ over a period of $10 \mathrm{~min}$ (a total of $4 \mathrm{ml}$ citric acid). Samples were collected for 2-min intervals. Tubing attached to the Lashley cups was kept as short as possible. and the dead space in the system was $0.1 \mathrm{ml}$.

Flow rate was assessed gravimet rically by weighing the sampling tubes before and after sample collection, and flow rate was expressed as milligrams per gland per min. Amylase was assayed on saliva diluted $1: 500$ or $1: 1,000$ in water by the hydrolysis of insoluble blue starch polymer to soluble blue starch fragments (28). Calcium, sodium, and potassium concentrations were measured by atomic absorption spectrophotometry after dilution of the saliva $1: 10$ in lanthanum chloride (La $5,000 \mathrm{ppm}$ ) for calcium (1I). 1:1,000 in potassium chloride ( $\mathrm{P} 100 \mathrm{ppm}$ ) for sodium, and 1:1,000 in sodium chloride ( $\mathrm{Na} 100 \mathrm{ppm}$ ) for potassium (9). Inorganic phosphate was assessed spectrophotometrically on saliva diluted $1: 5$ in $10 \%$ trichloroacetic acid by the molybdate-ascorbic acid method (7)

Student's $t$-test and linear regression were calculated using a Compucorp 445 Statistician computer (29) and appropriate mathematical tables.

\section{RESULTS}

\section{DURATION OF STIMULATION AND AMYLASE AND CALCIUM} CONCENTRATIONS

Two-minute interval studies of amylase concentration of stimu. lated parotid saliva (Fig. 1) showed a lag period of low amylase release lasting approximately 4 min after beginning stimulation. and an activated period of higher amylase release in the $6-10 \cdot \mathrm{min}$ period (Fig. I, a c). With low flow rates, the first 2-min sample sometimes had a high amylase concentration (Fig. $\mid a$ ) because of washout of resting saliva from the ducts. Amylase concentration often tended to plateau in the activated period (Fig. 1, $a$ and $b$ ). but sometimes continued to rise with time (Fig. Ic).

Calcium concentration began at relatively high levels, and rose further during the activated period, tending to parallel the amylase concentration pattern (Fig. 1, $a c$ c).

\section{FLOW RATE, AMYLASE, AND ELECTROLYTES OF CF AND CONTROL PAROTID SALIVA}

Flow Rate (Fig. 2a). Mean flow rates were low in the first 2-min samples because of a lag period after stimulation before saliva flow began. Thereafter, mean flow rates were reasonably stable. Although mean values were a little higher in the $\mathrm{CF}$ group. standard deviations were high, and the differences were not statistically different.

Amvlase (Fig. 2b). The CF group showed higher mean amylase levels than controls, but the wide variation of individual values and

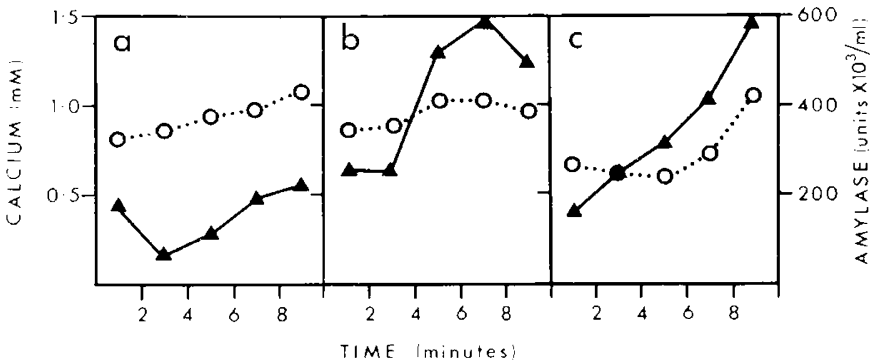

Fig. 1. Parotid function tests indicating the effects of resting saliva, a lag period of low amylase secretion, and an activated period of higher zymogen granule release. $a, b$ : cystic fibrosis children; $c$ : control child.

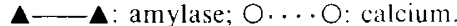
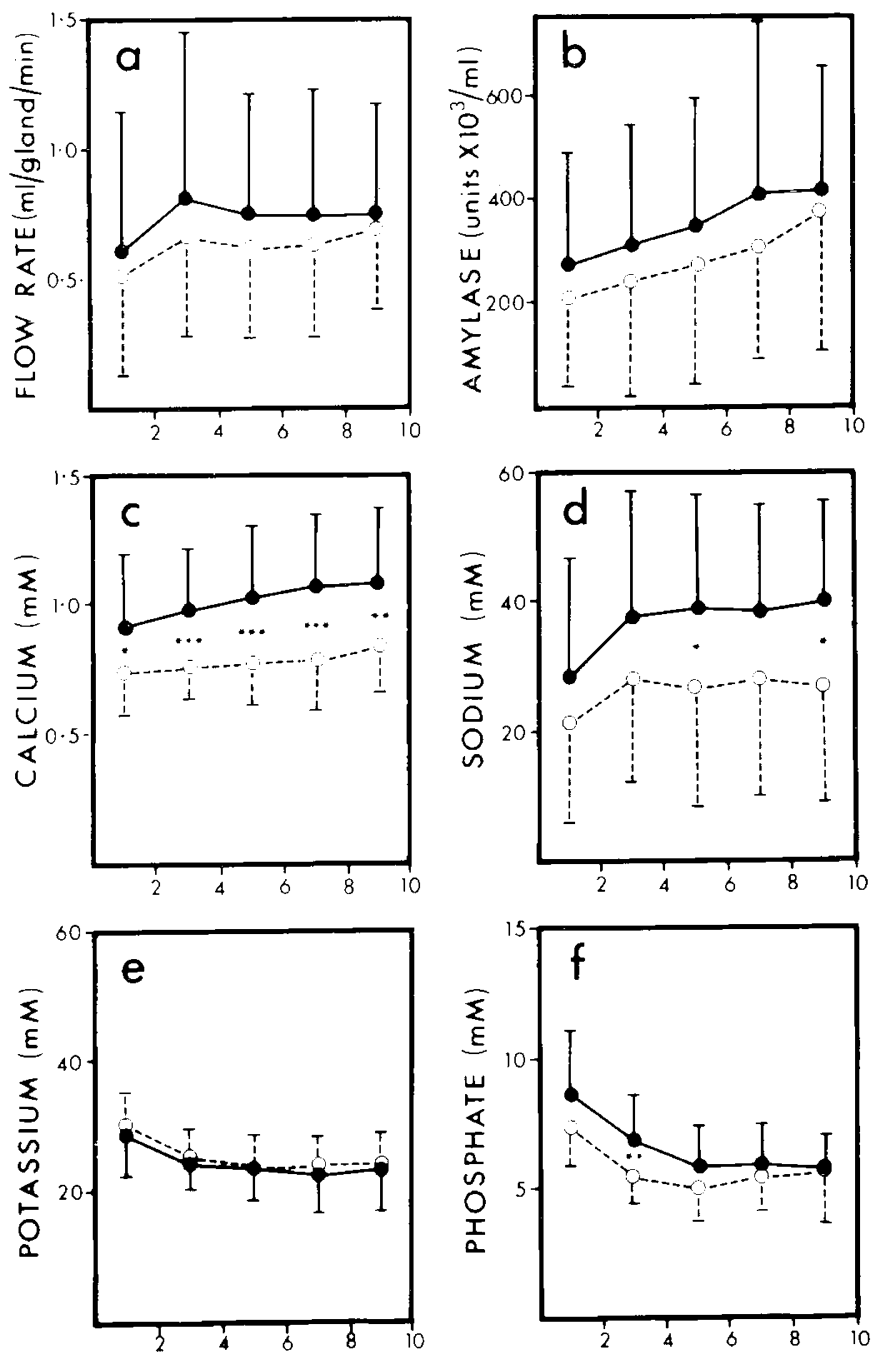

TIME (minutes)

TIME (minutes)

Fig. 2. Comparison of parotid function testing of 22 cystic fibrosis children and 21 control children, showing mean \pm SD for $(a)$ flow rate, $(b)$ amyliase, (c) calcium, (d) sodium, (e) potassium, and $(f)$ inorganic phosphate concentrations. cystic fibrosis children; $0-0$ : child cont rol subjects. ${ }^{*}: P<0.05$ or 0.02 ; $^{* *}: P<0.005$ : ${ }^{* *}: P<0.001$.

the large standard deviations in both $\mathrm{CF}$ and control groups rendered the higher CF values not statistically signilicant.

Calcium (Fig. 2C). The CF group had statistically significantly elevated mean calcium concentrations throughout the $10 \mathrm{~min}$ of stimulation $(P<0.02$ for the first 2 -min interval, $P<0.001$ for the second, third, and fourth intervals, and $P<0.005$ in the fifth sample). Although standard deviations about the means were small, there was appreciable overlap in values between the two groups.

Sodium (Fig. 2d). Initially low, mean sodium concentrations rose quickly to plateau levels. There was a wide scatter of sodium values among individuals. Mean sodium values were higher in the CF subjects, but were raised to a statistically significant level only in the $4-6-\min (P<0.05)$ and $8 \cdot 10-\min (P<0.02)$ samples.

Potassium (Fig. 2e). Potassium levels diminished during the first $4 \mathrm{~min}$ of stimulation to a lower steady state. Mean values were very similar in CF and control groups, and standard deviations about the means were low in both groups.

Inorganic Phosphate (Fig. 2f). The mean concentrations of inorganic phosphate fell during the first 4 min of stimulation to stable levels. The CF group tended to have higher inorganic phosphate values but the means were significantly different $(P<$ 0.005 ) only in the second sample. 
Table 1. Interrelationships between flow rate, amylase, and inorganic components of parotid saliva ${ }^{2}$

\begin{tabular}{|c|c|c|c|c|c|c|c|c|c|}
\hline \multirow{2}{*}{$\begin{array}{c}\mathrm{X} \\
\text { axis }\end{array}$} & \multirow{2}{*}{$\begin{array}{c}\mathrm{Y} \\
\text { axis }\end{array}$} & \multicolumn{4}{|c|}{ Child control subjects } & \multicolumn{4}{|c|}{ Cystic fibrosis } \\
\hline & & $n$ & $r$ & $P$ & $Y_{t m t}$ & $n$ & $r$ & $P$ & $Y_{\text {int }}$ \\
\hline \multirow[t]{5}{*}{ Flow rate } & Amylase & 63 & 0.24 & N.S. & & 66 & 0.16 & N.S. & \\
\hline & Calcium & 63 & 0.42 & $<0.001$ & 0.66 & 66 & 0.73 & $<0.001$ & 0.74 \\
\hline & Sodium & 63 & 0.47 & $<0.001$ & 11 & 66 & 0.56 & $<0.001$ & 24 \\
\hline & Potassium & 63 & -0.24 & N.S. & & 39 & -0.39 & $<0.05$ & 27 \\
\hline & Phosphate & 63 & -0.30 & $<0.05$ & 3.2 & 60 & -0.15 & N.S. & \\
\hline \multirow[t]{4}{*}{ Amylase } & Calcium & 63 & 0.58 & $<0.001$ & 0.68 & 66 & 0.28 & $<0.05$ & 0.96 \\
\hline & Sodium & 63 & 0.07 & N.S. & & 66 & 0.06 & N.S. & \\
\hline & Potassium & 63 & 0.31 & $<0.05$ & 22 & 39 & -0.12 & N.S. & \\
\hline & Phosphate & 63 & -0.14 & N.S. & & 60 & 0.48 & $<0.001$ & 2.4 \\
\hline \multirow[t]{3}{*}{ Sodium } & Calcium & 63 & 0.35 & $<0.01$ & 0.70 & 66 & 0.56 & $<0.001$ & 0.71 \\
\hline & Potassium & 63 & -0.47 & $<0.001$ & 27 & 39 & -0.77 & $<0.001$ & 33 \\
\hline & Phosphate & 63 & -0.20 & N.S. & & 60 & -0.02 & N.S. & \\
\hline \multirow[t]{2}{*}{ Potassium } & Calcium & 63 & 0.15 & N.S. & & 39 & -0.46 & $<0.01$ & 1.58 \\
\hline & Phosphate & 63 & -0.07 & N.S. & & 39 & 0.03 & N.S. & \\
\hline Phosphate & Calcium & 63 & -0.10 & N.S. & & 60 & -0.34 & $<0.01$ & 1.48 \\
\hline
\end{tabular}

${ }^{2}$ Flow rate expressed as milliliters per gland per min, amylase as Phadebas units $\times 10^{3} / \mathrm{ml}$, calcium, sodium, potassium, and inorganic phosphate as millimolar concentration. $n$ : number of pairs; $r$ : coefficient of correlation; $P=$ probability: $Y_{\text {int }}=Y$ intercept; N.S.: not significant.

INTERRELATIONSHIPS BETWEEN FLOW RATE. AMYLASE. AND ELECTROLYTES OF ACTIVATED SAMPLES

Activated parotid saliva samples were defined as the 2-min samples collected between 6 and $10 \mathrm{~min}$ after the beginning of citric acid stimulation. Correlation coefficients, statistical signifi. cance, and $\mathrm{Y}$-intercepts of all parameters for both child controls and $C F$ subjects are shown in Table 1.

Flow Rate. There were highly statistically significantly positive correlations between flow rate and calcium and sodium in activated saliva of both control and CF subjects. Flow rate was negatively correlated with inorganic phosphate in the control group and with potassium in the CF group. Flow rate did not correlate with amylase in either group.

Amylase. Amylase correlated with calcium in both groups (control $P<0.001$, CF $P<0.05$ ), with potassium in control saliva $(P<0.05)$, and with inorganic phosphate $(P<0.001)$ in $\mathrm{CF}$ saliva. The parallelism between amylase and calcium concentra tions in activated parotid saliva was also shown by estimating correlation coefficients for individual subjects. The means $( \pm \mathrm{SD})$ of these correlation coefficient were $0.50 \pm 0.48(P<0.001)$ for child controls and $0.43 \pm 0.72(P<0.001)$ for CF subjects

Calcium. Calcium concentrations were positively correlated with flow rate and with amylase and sodium concentrations in activated saliva of both control and $C F$ groups. There was an a mount of calcium of approximately $0.7 \mathrm{mM}$ which was independent of flow rate, amylase, or sodium (see Y-intercept, Table 1). Calcium did not correlate with potassium or phosphate in control saliva, and showed negative correlations with both these ions in $\mathrm{CF}$ saliva.

Sodium. There were positive correlations between sodium and flow rate and calcium for activated saliva of both groups, but not between sodium and amylase or phosphate. There were strong negative correlations $(P<0.001)$ between sodium and potassium in both groups of subjects.

Potassium. In addition to the strong negative relationships between potassium and sodium $(P<0.001)$ in the activated saliva of both groups, potassium was negatively correlated with flow rate $(P<0.05)$ and calcium $(P<0.01)$ in the $C F$ patients, and positively correlated with amylase $(P<0.05)$ in the control subjects.

Inorganic Phosphate. Inorganic phosphate was positively correlated with amylase $(P<0.001)$ in activated saliva of CF subjects but not in controls subjects, and was negatively correlated with flow rate $(P<0.05)$ in the control group. Phosphate showed no significant correlations with calcium, sodium, or potassium in saliva of either group.

\section{DISCUSSION}

The major difference between $C F$ and child control parotid saliva was in the elevated calcium concentrations in CF subjects. Previous studies using methacholine (18), prolonged chewing of chicle (6), $2 \%$ citric acid (25), or our previous 4 -min study using $5 \%$ citric acid (3) had shown increased calcium concentrations in $\mathrm{CF}$ parotid saliva, whereas other studies in which the gland was weakly stimulated by $2 \%$ citric acid (16) or orange lozenges (18) had not shown any difference. Lozenges or chicle are undesirable means of stimulation for comparative studies because differing rates of sucking or chewing influence flow rates, which in turn influence concentrations of inorganic and organic components $(8,9)$.

Amylase, although higher in the CF group, was not statistically significantly raised, which is in agreement with the data of $\mathrm{Mandel}$ et al. (15), but differs from our previous finding of higher amylase values in $\mathrm{CF}$ parotid saliva $(3,4)$. Elevation of amylase in $\mathrm{CF}$ parotid saliva therefore still remains in doubt.

Although our results indicated higher mean values for flow rates, sodium, and inorganic phosphate in CF children, statistical significance was minimal. Our potassium values were almost identical in CF and control saliva. In other studies, flow rate of stimulated parotid saliva in CF patients has been found to be statistically significantly greater than control subjects by some workers (18) but not different by others $(4,6.13)$. Significantly increased parotid saliva sodium concentrations were found in most studies $(4,6,12,18)$, but not in all (16). Inorganic phosphate has been found to be raised $(4,6,16)$. Potassium has consistently been found not to differ in $\mathrm{CF}$ patients $(4,6,12,16,18)$.

This investigation has confirmed studies on adult parotid saliva $(5,8,9)$ which indicated that stimulated saliva is a dynamically changing secretion varying widely in composition on converting from a resting to an activated state. In studies by Dawes $(8,9)$, flow rates were maintained at predetermined constant levels by varying the degree of sucking on sour lemon drops. In unstimulated parotid saliva, protein, calcium, potassium, and inor- 
ganic phosphate concentrations were high and sodium concentration was low. During approximately the first $3 \mathrm{~min}$ of stimulation. protein, calcium, potassium, and inorganic phosphate concentrations fell rapidly, and sodium concentration abruptly increased Thereafter, during the $15 \mathrm{~min}$ of stimulation, sodium, potassium. and phosphate concentrations remained constant, but protein and calcium concentrations tended to rise with the duration of stimulation. In our study. the first 2-min sample of stimulated saliva showed the influence of the unstimulated resting state and washout of the ducts in having low flow rate and sodium, high potassium and phosphate, and relatively low amylase and calcium values. The saliva then underwent a transient period covering the next 2 -min sample in which flow rate and sodium rose, potassium and phosphate diminished, but calcium and amylase release were not yet fully activated. After 4 min, flow rate and sodium values continued to be high, amylase and calcium release were activated. and potassium and phosphate fell to stable low levels. Sequential studies of CF and control saliva after cholinergic stimulation (methacholine) indicated similar rises with time in flow rate, sodium, and calcium in the stimulated saliva (18). This pattern of activation suggests that parotid saliva collected for comparative studies between CF and control subjects should be collected under carefully controlled conditions using a constant stimulus and a clearly defined duration of stimulation.

In the activated parotid saliva samples, the positive correlations between flow rate and calcium and flow rate and sodium, and the negative correlations between flow rate and potassium (CF saliva) and inorganic phosphate (control saliva) are in agreement with reports by Dawes $(8.9)$, in which subjects maintained constan flow rates by variation in degree of sucking on sour lemon drops, and with our study of healthy adult subjects (5), using the same constant citric acid stimulus employed in the present study. Both of the adult studies found positive correlations between flow rate and amylase which were not evident in the present investigation.

The influence of flow rate on the level of sodium in the saliva is thought to be due to primary secretion of sodium in the acinar region at isotonic concentration and rate-limited reabsorption of sodium during its passage along the salivary ducts (21). Higher sodium concentrations found in CF saliva have been attributed to an as yet unidentified factor inhibiting reabsorption of sodium (17). The negative correlations between sodium and potassium probably reflect exchange of potassium for sodium during reab. sorption by $\mathrm{Na}^{+}, \mathrm{K}^{+}$-ATPase

The correlation between amylase and calcium may be of importance in understanding the production of abnormal secretions in CF exocrine glands. The parallelism between amylase and calcium concentrations suggests an association between release of the two, with calcium possibly being an integral component of the zymogen granules, as proposed for rat parotid gland (23), or possibly permeating across the luminal membrane during mem. brane depolarization, just before zymogen granule fusion and amylase release, as found in the mouse pancreas (19). A substantial amount of the calcium in parotid saliva appears to be independent of amylase release $(0.68 \mathrm{mM}$ calcium in the control group: $0.96 \mathrm{mM}$ in the CF group), and thus is probably secreted with the watery component of saliva. This appears to be similar to calcium release into pancreatic juice, where part of the calcium parallels amylase release, but part, in the secretin-induced. aqueous, electrolyte-rich fraction, is independent of amylase or protein release $(10)$.

The higher calcium concentration of parotid saliva of $\mathrm{CF}$ patients is probably a major factor in the increased incidence and amount of dental calculus found on the upper molars of $\mathrm{CF}$ children (26). Coprecipitation of protein with the calcium phosphate $(1,2)$ is probably also an important factor in attaching the dental calculus to the enamel surface of the teeth and in forming an organic matrix for further calcification. Formation of insoluble calcium-phosphate-protein complexes in CF parotid gland acinar lumina and small ducts is presumably the cause of the atrophic acini and ductal distension by "inspissated mucins" observed in CF parotid glands (22).
The parotid function test, as applied under our experimental conditions and in the age range studied, has no value as a diagnostic test for cystic fibrosis. Even calcium values, which, as a group, are significantly elevated in CF subjects, show too much overlap with control subjects to be of diagnostic worth. We have not looked at unstimulated parotid saliva, nor have we investigated parotid saliva of infants, so that our results do not give any indication of the potential value of the sodium electrode as a screening test for cystic fibrosis in infants $(14,20,24)$.

\section{SUMMARY}

Citric acid-stimulated parotid saliva took approximately $4 \mathrm{~min}$ to reach an activated state, with flow rate, amylase, calcium and sodium values tending to rise and potassium and inorganic phosphate to fall during this period. In comparisons between $\mathrm{CF}$ and control saliva, calcium concentrations were highly statistically significantly elevated in the CF saliva. Flow rate, amylase, and sodium values of both $C F$ and control saliva showed wide standard deviations about the means, and although higher in the CF patients, were only minimally statistically significantly different. Potassium and inorganic phosphate concentrations were similar in the two groups of subjects, with significantly elevated inorganic phosphate only in the 2-4-min period.

In the 6-10-min-activated secretion period, there were statisti. cally significant positive correlations between flow rate and calcium, flow rate and sodium, amylase and calcium, amylase and potassium (control), amylase and phosphate (CF), and sodium and calcium. Significant negative correlations were found between flow rate and potassium (CF), flow rate and inorganic phosphate (control), sodium and potassium, potassium and calcium (CF), and inorganic phosphate and calcium (CF). Although calcium and amylase correlated significantly, a substantial amount of calcium was independent of amylase $(0.68 \mathrm{mM}$ in control and $0.96 \mathrm{mM}$ in CF saliva).

\section{REFIRENCES AND NOTHS}

1. Allars. H. M. Blomfield. J., Rush, A. R., and Brown, J. M. Colloid and crystal formation in parotid saliva of cystic fibrosis patients and non-cystic fibrosis subjects. I. Physicochemistry. Pediat. Res.. 10:000 (1976).

2. Allars, H. M., Cockayne. D. J. H.. Blomfield. J., Rush. A. R., van Lennep, E. W and Brown. J M . Colloid and crystal formation in parotid salivat of cystic fibrosis patients and non-cystic librosis subjects. 11. Electron microscopy and electrophoresis. Pediat. Res., 10:000 (1976).

3. Blomfield, J., Allars, H. M., Rush, A. R., van Lennep, E. W., and Brown, J. M. Parotid serous hypersecretion in cystic fibrosis. Aust. Paediat. J.. 10: 75 (1974)

4. Blomfield, J., Allars, H. M., Rush. A. R., van Lennep, E. W.. and Brown. J. M. Parotid saliva of cystic fibrosis homozvgotes and heterozygotes. Cystic Fibrosis Club Abstracts. 15th Annual Meeting. Washington, D.C.. p. 29 (National (ystic Fibrosis Rescalrch Foundation. Atlanta. 1974)

5. Blomfield, J., Rush, A. R., and Allars, H. M.: Interrelationships between flow rate, amylase, calcium, sodium, potassium, and inorganic phosphate in interval studies of citric acid stimulated parotid saliva of young adults. Arch. Oral Biol. (In press.)

6. Chauncey, H. H., Levine, 1). M., Kass, G.. Shwachman. H., Henriques, B. L. and Kulcayeki. L. I..: (omposition of human saliva: Parotid gland secretory rate and electrolyte concentration in children with cystic fibrosis. Arch. Oral Bici., 7. 707 (1962).

7. Chen. P. S. Toribara, T. Y. and Warner, H.: Microdetermination of phosphorus. Anal. Chem., 28: 1756 (1956)

8. Dawes, $C$.: The secretion of magnesium and calcium in human parotid saliva. Caries Res., 1: 333 (1967).

9. Dawes, C.: The effects of flow rate and duration of stimulation on the concentrations of protein and the main electrolytes in human parotid saliva. Arch Oral Biol, 14. 277 (1969).

10. Gocbell. H.. Steffen, C.. and Bode. C.: Stimulatory effect of pancreorymin cholecystokinin on cialcium secretion in pancreatic juice of dogs. Gut, 13:477 (1972).

11. Gow, B. S.: Analysis of metals in saliva by atomic absorption spectroscopy. I Calcium. J. Dent. Res., 44: 885 (1965)

12. Johnston, W. H.: Salivary electrolytes in fibrocystic disease of the pancreas. Arch. Dis. Childhood, 31: 477 (1956).

13. Kutscher, A. H., Mandel, I. D.. Thompson, R. H.. Wotman, S., Zegarelli, E. V. Fahn, B. S., Denning, C. R., Goldstein, J. A., Taubman, M., and Khotim, S. Parotid saliva in cystic fibrosis I. Flow rate. Amer. J. Dis. Child. 1/0: 643 (1965).

14. Lawson, D., Westcombe, P., and Saggers, B.: Pilot trial of an infant screening programme for cystic fibrosis: Measurement of parotid salivary sodium at 4 months. Arch. Dis. Childhood, 44: 715 (1969). 
15. Mandel, I. D., Kutscher, A., Denning. C. R., Thompson, R. H., and Zegarelli, F. V.: Salivary studies in cystic fibrosis. Amer. J. Dis. Child., 113: 431 (1967).

16. Mandel, 1. D.. Thompson, R. H., Wotman, S., Taubman, M., Kutscher, A. H. Zegarelli, E. V.. Denning, C. R., Botwick, J. T. and Fahn, B. S.: Parotid saliva in cystic fibrosis. II. Electrolytes and protein-hound carbohydrates. Amer. J. Dis. Child.. 110:646 (1965)

17. Mangos. J. A.. McSherry. N. R., and Benke, P. J.: A sodium transport inhibitory factor in the saliva of patients with cystic fibrosis of the pancreas. Pediat. Res. I: 436 (1967).

18. Marmar, J., Barbero, (j. J., and Sibinga. M. S.: The pattern of parotid gland secretion in cystic fibrosis of the pancreas. Gastroenterology, 50:551 (1966).

19. Matthews, E. K.. Petersen, O. H., and Williams, J. A.: Pancreatic acinar cells Acetylcholine-induced membrane depolarization, citlcium efflux and amylase releise. J Physiol 234:689 (1973)

20. Saggers. B. A.. Lawson. D.. Stern, J.. and Edgsin, A. C.: Rapid method for the detection of cystic fibrosis of the pancreas in children. Arch. Dis. Childhood 42: $187(1967)$.

21. Schneyer, L. H., Young. J. A.. and Schnever, C. A.: Salivary secretion of electrolytes. Physiol. Rev.. 52: 720 (1972).

22. Shackleford, J. M., and Bentley, H. P.: Carbohydrate histochemistry of the salivary glands and pancreas in cystic fibrosis. J. Histochem. Cytochem., 12.

Copyright (c) 1976 International Pediatric Research Foundation, Inc.
$512(1964)$.

23. Wallach, D., and Schramm, M.: Calcium and the exportable protein in rat parotid gland: Parallel subcellular distribution and concomitant secretion. Eur. J. Biochem., 2l: 433 (1971)

24. Wiesmann, U. N., Boat, T. F., and di Sant'Agnese, P. A.: Sodium concentration in unstimulated parotid saliva and on oral mucosa in normal subjects and in patients with cystic fibrosis. J. Pediat.. 76: 444 (1970).

25. Wotman, S., Mandel, I. D., Mercadante, J., and Denning. C. R.: Parotid and submaxillary calcium in human cystic fibrosis. Arch. Oral Biol., 16: 663 (1971).

26. Wotman, S., Mercandante, J., Mandel, I. D., Goldman, R. S., and Denning. C. The occurrence of calculus in normal children, children with cystic fibrosis, and children with asthma. J. Periodontol., 44: 278 (1973).

27. H \& I Instrumentation, Teaneck, N. J

28. Phadebas Amylase Test, Pharmacia AB, Uppsala, Sweden.

29. Computer Design Corporation, Los Angeles, Calif.

30. This research was supported in part by The Clive and Vera Ramaciott Foundations and The Cystic Fibrosis Association of New South Wales.

31. Requests for reprints should be addressed to: J. Blomfield. M.Sc. Children' Medical Research Foundation, P.O. Box 61. Camperdoun, N.S.W 2050 (Australia).

32. Accepted for publication December 18, 1975.
Calcium

cystic fibrosis inhibitors inorganic phosphate

\title{
Colloid and Crystal Formation in Parotid Saliva of Cystic Fibrosis Patients and Non-Cystic Fibrosis Subjects. I. Physicochemistry
}

\author{
HELEN M. ALLARS, JEANETTE BLOMFIELD, ${ }^{34}$ ANNE: R. RUSH, AND JOHN M. BROWN \\ Children's Medical Research Foundation and Cystic Fibrosis Clinic, Royal Alexandra Hospital for Children,
} Sydney, New South Wales, Australia

\section{Extract}

Two types of turbidity were found in parotid saliva from both cystic fibrosis ( $(F)$ patients and non- $(F$ subjects. On cooling saliva, a rapidly forming, rerersible, cold-dependent turbidity appeared in increasing amounts with decreasing temperature and increasing protein concentration. At $37^{\circ}$, a slowly forming, stable turbidity appeared in increased amounts in parotid saliva samples containing increased amounts of calcium. The $2^{\circ}$ centrifuged pellet consisted predominantly of protein, whereas the $37^{\circ}$ peliet contained calcium, inorganic phosphate, and protein. The cold-dependent turbidity at $2^{\circ}$ was not inhibited by EDTA, but $37^{\circ}$ turbidity was dramatically inhibited. Lrea and guanidine hydrochloride reduced 2 turbidity, and, to a lesser extent, inhibited 37 turbidity. The tendency towards higher levels of protein, amylase, and calcium in ( $\mathrm{F}$ compared with child control parotid saliva $(4,6)$ causes a greater incidence and degree of turbidity formation in saliva of $C F$ patients. In this paper only the nature of the turbidity has been investigated, not its relative occurrence in each group of subjects.

\section{Speculation}

In cystic fibrosis, a tendency towards high levels of calcium and protein in parotid saliva would mediate towards deposition of colloidal protein and calcium phosphate within parotid gland ducts and on tooth surfaces adjacent to duct orifices. A similar oversecretion of calcium and protein in other $C F$ exocrine secretions may result in obstruction by stagnant or cooled secretions.
Parotid saliva from patients with $\mathrm{CF}$ and control subjects is clear as collected, but saliva with elevated protein (amylase) and calcium concentrations becomes turbid on standing (4). Cystic fibrosis patients tend to have parotid salivat with higher amylase and calcium concentrations than age-matched child control subjects $(4,6)$, and turbidity formation is therefore encountered more frequently and to a greater degree in parotid saliva of $C F$ paltients. Aspects of physicochemical properties of this turbidity formation. particularly in relation to temperature and to protein. calcium, and phosphate concentrations, are recorded in this paper, and electron microscope appearance and electrophoretic properties of the insoluble material are reported in a subsequent paper (2). In this paper only the nature of the turbidity has been investigated. not its relative occurrence in each group of subjects

\section{SUBJECTS AND MHTHODS}

\section{SAIIVA COI.I.ECTION}

Subjects for the study were 13 cystic fibrosis patients aged $8 \quad 13$ years (attending the Cystic Fibrosis Clinic at the Royal Alexandra Hospital for Children), and 7 young adult non-CF subjects aged 1824 years (hospital staff). To some extent subjects were selected from those known to have a high parotid saliva flow rate and high protein and calcium concentrations, in whom the saliva had been noted in previous studies $(4,6,7)$ to become turbid on standing at room temperature. 